\title{
Controle biológico de formigas-cortadeiras: o caso da predação de fêmeas de Atta spp. por Canthon virens
}

\author{
Márcio da Silva Araújo ${ }^{1}$, Camila Alves Rodrigues ${ }^{1}$, Marco Antônio de Oliveira², Flávio \\ Gonçalves de Jesus ${ }^{3}$ \\ ${ }^{1}$ Universidade Estadual de Goiás - UEG, Ipameri, GO, Brasil. E-mail: marcio.araujo@ueg.br; camilaalvesrodrigues@hotmail.com \\ ${ }^{2}$ Universidade Federal de Viçosa - UFV, Viçosa, MG, Brasil. E-mail: marco.oliveira@ufv.br \\ ${ }^{3}$ Instituto Federal Goiano - IFGOIANO, Urutaí, GO, Brasil. E-mail: fgjagronomia @ zipmail.com.br
}

Recebido: 13/08/2015; Aceito: 04/09/2015.

\section{RESUMO}

As formigas-cortadeiras são importantes pragas dos setores agrícola e florestal do Brasil. O controle dessa praga, em geral, tem sido realizado com uso de inseticidas químicos, especialmente iscas formicidas envenenadas. Formas alternativas ao controle químico são conhecidas e podem representar significativo controle dessa praga, entretanto são pouco estudadas. O propósito deste texto é discorrer sobre aspectos bioecológicos e perspectivas de uso de um característico predador de fêmeas de Atta Fabricius, 1804 (Hymenoptera: Formicidae), o besouro predador Canthon virens Mannerhein (1929) (Coleoptera: Scarabaeidae). Esse predador, comumente encontrado em áreas de cerrado do Brasil, decapta as fêmas de saúvas assim que elas aterrizam ao solo pós voô nupcial ou revoada. Essa presa abatida é transportada para o interior de seus ninhos construídos no solo e servirá de alimento para as suas larvas.

Palavras-chave: saúvas, biocontrole, tanajuras, vôo nupcial, besouros coprófagos.

\section{Biological control of leaf-cutting ants: the case of Atta spp. females predation by Canthon virens}

\begin{abstract}
The leaf-cutting ants are important pests of agriculture and forestry sectors in Brazil. The control of this pest, in general, has been carried out with the use of chemical pesticides, especially insecticides poisoned baits. Alternative methods to chemical control are known and can represent significant control of this pest, however, are little studied. The purpose of this review is to discuss about bioecological aspects and perspectives for use of a typical predator of Atta Fabricius females, 1804 (Hymenoptera: Formicidae), the beetle predator Canthon virens Mannerhein (1929) (Coleoptera: Scarabaeidae). This predator, commonly found in savanna areas of Brazil, decapitate the female of Atta during and post nuptial flight. This felled prey is transported into their nests in the ground and serve as food for their larvaes.
\end{abstract}

Key words: Leaf-cutter ants, biocontrol, female, nuptial flight, dung beetles. 


\section{Introdução}

As saúvas (Atta) e as quenquéns (Acromymex Mayr, 1865), juntamente com outros 14 gêneros, compõem a tribo Attini (Formicidae cultivadoras de fungo) (BOLTON et al., 2006). Estes gêneros estão distribuídos desde o sul dos Estados Unidos (latitude $33^{\circ} \mathrm{N}$ ) até o centro da Argentina (33 $\left.{ }^{\circ} \mathrm{S}\right)$ (MARICONI, 1970; DELABIE et al., 2011). Além do maior tamanho de suas colônias, saúvas e quenquens, retratadas como "as verdadeiras formigas-cortadeiras", utilizam folhas frescas, brotações e flores como substrato para o cultivo de seu fungo, e por esse motivo são consideradas pragas potencias para as atividades agrícolas e florestais. Os demais gêneros de Attini utilizam, principalmente, matéria orgânica morta, fezes e carcaças de insetos para o mesmo fim (HÖLLDOBLER; WILSON, 1990).

Os prejuízos acarretados pelas formigas-cortadeiras foram retratados desde o descobrimento do Brasil. Frase como a do naturalista Francês August de Saint-Hilaire (1779-1853): “ou o Brasil acaba com a saúva ou a saúva acaba com o Brasil", tornou-se famosa. O alerta desse naturalista feito no início do século XIX, nos dias atuais, soaria como um enorme exagero. Entretanto, é bom retratar que, mesmo com esforços desprendidos para conhecer esses insetos-praga, bem como desenvolver novas táticas de controle, as formigascortadeiras continuam sendo as principais pragas da agricultura e do setor florestal do Brasil (DELLA LUCIA; SOUZA, 2011).

Uma expressiva quantidade de defensivos agrícolas na formulação formicida (iscas granuladas, pós-secos, pós-solúveis e líquidos termonebulizáveis) tem sido comercializada no Brasil nos últimos anos, principalmente para o controle de saúvas (OLIVEIRA et al., 2011). Além do elevado custo dos formicidas e da operação de combate a essas formigas, o uso intensivo desses agrotóxicos a cada dia que passa, é fortemente questionado por consumidores cada vez mais exigentes por produtos ambientalmente seguros.

Por essas questões ambientais e econômicas, se faz importante investigar métodos alternativos de controle das formigas-cortadeiras. Entretanto, devido à carência de pesquisas científicas pouco se conhece a respeito desses métodos alternativos de controle (ARAÚJO et al., 2003). Métodos alternativos de controle de formigas-cortadeiras como: inseticidas fisiológicos, plantas e produtos naturais, controle cultural, métodos mecânicos e físicos, controle comportamental e controle biológico podem ser consultados em livro editado por Della Lucia (2011).

O controle biológico é o componente fundamental do equilíbrio da natureza, cuja essência está baseada no mecanismo de densidade recíproca, isto é, com o aumento da densidade populacional da presa, ou hospedeiro, os predadores, ou os parasitos, tendo maior quantidade de alimento disponível, também aumentam em número. Desta forma, segundo Berti Filho (1990), os inimigos naturais causam declínio na população do inseto-praga.

Neste texto são abordados aspectos relacionados a alguns potenciais limitadores do estabelecimento de novas colônias de formiga-cortadeira Atta sp., dando ênfase ao comportamento predatório do besouro Canthon virens Mannerhein (1929). O Canthon virens (Coleoptera: Scarabaeidae) tem sido apontado com um excelente predador de fêmeas (tanajuras) de saúvas, no entanto, este comportamento predatório para a região do Cerrado brasileiro é pouco conhecido.

\section{Revisão de Literatura}

\subsection{Revoadas e estabelecimento de ninhos de Atta}

A revoada ou vôo nupcial é uma estratégia reprodutiva adotada pelas formigas-cortadeiras, que culmina com o acasalamento, a dispersão e o estabelecimento de novas colônias (MARINHO et al., 2011). É um fenômeno bastante característico da espécie. Em Atta sp., ocorre em colônias sexualmente maduras, o que geralmente se dá 38 meses após a data de fundação da colônia, sendo o processo repetido todos os anos (MARICONI, 1970).

Em geral, antes do vôo nupcial - em torno de 30 minutos - pode-se observar uma intensa e atípica movimentação de soldados e operárias agressivas sob o formigueiro, seguidas pelos bitus (machos) e tanajuras (fêmeas) que saem em revoada (DELLA LUCIA; BENTO, 1993). Segundo Fowler (1982), a excitação das operárias de Atta imediatamente antes e durante a revoada é iniciada em resposta às secreções mandibulares dos machos. Esse comportamento confere proteção às formas sexuadas contra eventuais predadores e, também, parece preparar as operárias para executar tanajuras que tentem estabelecer suas colônias próximas às colônias adultas onde ocorreu a revoada.

Essa revoada ocorre de maneira sincrônica entre indivíduos de diferentes colônias da mesma espécie e, até mesmo, de espécies diferentes (DELLA LUCIA; BENTO, 1993). Tal comportamento, além de favorecer recombinações gênicas, facilita a dispersão das fêmeas acasaladas pelas correntes de ar. Segundo Hölldobler \& Wilson (1990), a dispersão para o acasalamento ocorre quando fatores climáticos como precipitação, umidade relativa, temperatura e velocidade do vento dão aos machos e fêmeas as melhores chances para acasalamento, escape de predadores e localização de um sítio adequado para a fundação de novas colônias.

As revoadas de saúvas, geralmente, ocorrem após a ocorrência de chuvas que umedecem o solo (ARAÚJO et al., 2003). Isso poderia não só facilitar a escavação do ninho, como também constituir um microambiente mais 
favorável ao cultivo inicial do fungo simbionte (VASCONCELOS, 1990; ARAÚJO et al., 2003).

$\mathrm{O}$ período entre a revoada e a construção do novo ninho é o mais crucial da vida de uma colônia de formiga (HÖLLDOBLER; WILSON, 1990). Assim, compreendermos os fatores de mortalidade natural dessas relevantes pragas se faz importante para proposição de manejo.

\subsection{Predação de tanajuras}

Das tanajuras que saem em revoada, 99,95\% não dá origem a sauveiros adultos (AUTUORI, 1950). O não estabelecimento de novas colônias de Atta spp. está diretamente associado à alta mortalidade das fêmeas devido às chuvas fortes e abundantes (MARICONI, 1970), aos microorganismos de ocorrência natural nos solos (BENTO et al., 1991; ARAÚJO et al., 2003; RODRIGUES et al., 2010) e, à predação por diversos grupos de animais, incluindo outros insetos e o próprio homem, que as utilizam como alimento (ANJOS et al., 1998; SILVEIRA et al., 2006; RODRIGUES et al., 2010, ARAÚJO et al., 2011).

Essa fase crítica para formação de novas colônias inicia-se quando as fêmeas virgens aparecem na superfície do ninho materno para saírem em revoada. Nessa fase, elas são capturadas, principalmente, por pássaros e aves domésticas (ANJOS et al., 1998). Igualmente críticas são as fases onde as fêmeas recém fecundadas caem no solo e iniciam a busca por local onde estabelecer seu ninho e, também, durante a escavação do ninho, onde continuam sendo presas relativamente fáceis de aves, sapos, lagartos e outros artrópodes (AUTUORI, 1950). Destes, segundo Araújo et al. (2011), merece atenção o Canthon virens (Coleoptera: Scarabaeidae), por se tratar de predador específico de iças.

\subsection{Os besouros predadores de saúvas}

Os besouros "rola-bostas" ou "besouros-do-esterco" fazem parte da sub-família Scarabaeinae. Sua maior diversidade se dá em florestas e savanas tropicais
(HANSKI; CAMBEFORT, 1991). São insetos cosmopolitas, que se alimentam primariamente de fezes (coprófagos). A maioria deles tem por hábito, enterrar porções de fezes, carcaças e frutos em decomposição (SILVA et al., 2010) em túneis escavados próximos ao depósito de recursos, com os quais se alimentam e produzem suas progênies (FORTI et al., 2012). Os mais característicos são aqueles que fazem porções "pílulas" de fezes de bovinos depositadas em áreas de pastagem (com auxílio de suas pernas anteriores) e as rolam até o ninho (com auxílio de suas pernas posteriores) (LIMA, 1953).

Parcos estudos têm documentado um atípico comportamento de abandono do hábito da coprofagia em Scarabaeinae. Esse hábito é verificado em duas espécies de Canthonine. Canthon virens e Deltochilum valgum Burmeister, 1873 são retratadas como predadores específicos de fêmeas de Atta spp. e milípodes, respectivamente (SILVEIRA et al., 2006; LARSEN et al., 2009). Particularmente, para $C$. virens, além de tanajuras, Vaz-de-Melo et al. (1998) mencionaram que os insetos adultos também se alimentam de fezes de mamíferos, como as do lobo guará (Chrysocyon brachyurus Illiger, 1815) e, frutos maduros.

Hertel \& Colli (1998), Silveira et al. (2006), Araújo et al. (2011) e Forti et al. (2012) descreveram o comportamento de predação $C$. virens, desde a aproximação da presa, a típica maneira de "monta" na região notal do tórax, a preparação para decaptação e a decaptação da presa, o transporte "rolamento" da presa abatida até o ninho e, o enterrio da mesma no ninho. Uma vez que a maioria dos casos de predação era realizada pelo macho solitário, Silveira et al. (2006) mencionaram a possibilidade de ele usar, também, a tanajura abatida como atrativo de fêmeas para a cópula. Com a finalidade de ilustrar predador e presa, na figura 1 é mostrado um registro de ataque do predador $C$. virens à fêmea de Atta sexdens Linnaeus, 1758, em região de cerrado de Goiás, Brasil.
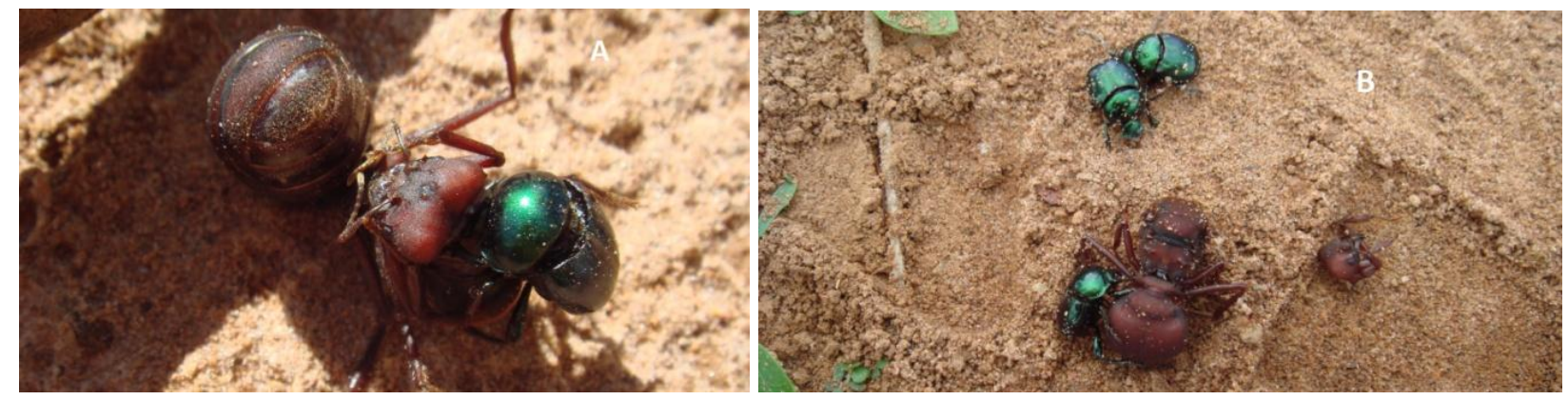

Figura 1. (A) Registro do momento da decapitação de uma fêmea de Atta sexdens por Canthon virens, em dia de revoada. (B) Após a decapitação, o mesmo besouro preparando para iniciar o "rolamento" da presa até o futuro ninho que será construído e, registro da chegada de mais dois predadores, pós-decapitação. Ipameri, GO, Brasil, novembro de 2013. (Fotos: M.S. Araújo). 
A presença de besouro $C$. virens tem sido documentada em vegetação de cerrado (VAZ-DEMELLO, 1998; SILVEIRA et al., 2006). Forti et al. (1999) constataram, em condições de campo, que, na maioria das vezes, o número de rainhas predadas aumenta não-linearmente com a densidade do predador e, que devem existir fatores isolados ou combinados que atuem como limitantes do número de presas exploradas. Esses mesmos autores mencionaram, ainda, como aspecto negativo de um eventual uso desse predador como agente eficiente de controle biológico, o reduzido potencial reprodutivo de fêmeas da espécie. Junto a isso, deve-se levar em conta, que é comum, verificar o ataque de besouros em grupo (machos e fêmeas) em uma única tanajura (SILVEIRA et al., 2006). De 19 tanajuras observadas por Silveira et al. (2006), somente num caso, a fêmea do besouro atacou sozinha. Esses autores sugerem que essas fêmeas desempenhariam um comportamento oportunista, uma vez que elas atacam somente na presença, de no mínimo, um macho. Além de todas essas limitações, Silveira et al. (2006) observaram que as tanajuras podem, em muito dos casos, remover com sucesso, o predador de suas costas. Assim, por essas questões e pela efetiva baixa taxa de predação verificada em campo, Boaretto \& Forti (1997) e Forti et al. (1999) mencionaram o insucesso da criação e introdução no campo (controle biológico clássico) para controle de saúvas no Paraguai, iniciado em 1950.

Apesar da não indicação para controle biológico clássico, conforme mencionado anterior, nas áreas de ocorrência natural esse besouro predador tem sido um dos relevantes componentes de impedimento de infestação de novas colônias de saúvas, assim, trabalhos futuros devem ser desenvolvidos com o intuito de entender a dinâmica predador/presa/ambiente.

\section{Considerações Finais}

A descrição do comportamento de captura de fêmeas de Atta spp. por Canthon virens, por ser bem característico, tem sido relativamente bem documentada em literatura. Entretanto, a ocorrência natural de Canthon virens em local restrito (algumas regiões de cerrado brasileiro), a dificuldades de monitoramento de revoada de tanajuras e a efemeridade desse evento, explicariam a escassez de estudo bioecológicos sobre esse predador de saúvas. Entretanto, os parcos estudos divulgados até então, relatam esse predador como relevante agente de controle biológico natural, impedindo o estabelecimento de novas colônias de saúvas.

\section{Referências Bibliográficas}

ANJOS, N.; DELLA LUCIA, T. M. C.; MAYHÉ-NUNES, A. J. Guia prático sobre formigas cortadeiras em reflorestamentos. Ponte Nova-MG: Graff Cor Ltda., 1998. $97 \mathrm{p}$.

ARAÚJO, M. S.; DELLA LUCIA, T. M. C.; RIBEIRO, G. A.; KASUYA, C. M. Impacto da queima controlada da cana-deacúcar na nidificação e estabelecimento de colônias de Atta bisphaerica Forel (Hymenoptera: Formicidae). Neotropical Entomology, Londrina-PR, v. 32, p. 685-691, 2003.

ARAÚJO, M. S.; PEREIRA, J. M. M.; RIBEIRO, M. M. R.; OLIVEIRA, M. A. Predadores e outros organismos associados aos ninhos de formigas-cortadeiras. In: DELLA LUCIA, T. M. C. Formigas-cortadeiras: da biologia ao manejo. ViçosaMG: UFV, 2011. p 311-320.

AUTUORI, M. Contribuição para o conhecimento da saúva (Atta spp. Hymenoptera-Formicidae). V- Número de formas aladas e redução dos sauveiros iniciais. Arquivos do Instituto Biológico, São Paulo-SP, v. 19, p. 325-331, 1950.

BENTO, J. M. S.; DELLA LUCIA, T. M. C.; MUCHOVEJ, R. M. C.; VILELA. E. F. Influência da composição química e da população microbiana de diferentes horizontes do solo no estabelecimento de sauveiros iniciais de Atta laevigata (Hymenoptera: Formicidae) em laboratório. Anais da Sociedade Entomológica do Brasil, Londrina-PR, v. 20, p. 307-317, 1991.

BERTI FILHO, E. O controle biológico dos insetos-praga. In: CROCOMO, W.B. Manejo integrado de pragas. São PauloSP: CETESB, 1990. p. 87-104.

BOARETTO, M. A. C.; FORTI L. C. Perspectivas no controle de formigas cortadeiras. Série Técnica IPEF, Piracicaba-PR, v. 11, p. 31-46, 1997.

BOLTON, B.; ALPERT, G.; WARD, P.S.; NASKRECKI, P. Bolton's catalogue of ants the world. 1758-2005. Cambridge: Harvard University Press, 2006. CD-ROM.

DELABIE, J. H. C.; ALVES, H. S. R.; REUSS-STRENZEL, G. M.; CARMO, A. F. R.; NASCIMENTO, I. C. Distribuição das formigas-cordadeiras dos gêneros Acromyrmex e Atta no Novo Mundo. In: DELLA LUCIA T. M. C. Formigascortadeiras: da biologia ao manejo. Viçosa-MG: UFV, 2011. p. $80-101$.

DELLA LUCIA, T. M. C.; SOUZA, D. J. Importância e história de vida das formigas-cortadeiras. In: DELLA LUCIA, T. M. C. Formigas-cortadeiras: da biologia ao manejo. Viçosa-MG: UFV, 2011. p. 13-26.

DELLA LUCIA, T. M. C.; J. M. BENTO. Vôo nupcial ou revoada, In: DELLA LUCIA, T. M. C. As formigas cortadeiras. Viçosa-MG: Folha de Viçosa, 1993. p. 54-59.

FORTI, L. C.; RINALDI, I. M. P.; CAMARGO, R. S.; FUJIHARA, R. T. Predatory behavior of Canthon virens (Coleoptera: Scarabaeidae): a predator of leafcutter ants. Psyche, New York, p.1-5, 2012.

FORTI, L. C.; RINALDI, I. M. P.; YASSU, W.; PINHÃO, M. A. S. Avaliação da eficiência de predação de Canthon virens (Coleoptera, Scarabaeidae). Naturalia, Rio Claro-SP, v. 24, p. 241-242, 1999.

FOWLER, H. G. Male induction and function of workers excitability during swarming in leaf-cutting ants (Atta and Acromyrmex) (Hymenoptera, Formicidae). International Journal of Invertebrate Reproduction, Abingdon, v. 4, p. 333-335, 1982.

HANSKI. I.; CAMBEFORT, Y. Dung beetle ecology. Princeton, Princeton University Press, 1991. 249 p. 
HERTEL, F.; COLLI, G. R. The use of leaf-cutter ants as a substrate for oviposition by dung beetles in Central Brazil. The Coleopterists Bulletin, Washington, v. 52, p. 105-108, 1998.

HÖLLDOBLER, B.; WILSON, E. O. The ants. Cambridge: Harvard University Press, 1990. 732 p.

LARSEN, T. H.; LOPERA, A.; FORSYTH, A.; GÉNIER, F. From coprophagy to predation: a dung beetle that kills millipedes. Biology Letters, London, v. 5, p. 152-155, 2009.

LIMA, C. Insetos do Brasil: coleópteros. $2^{\mathrm{a}}$ parte. Rio de Janeiro_RJ: Escola Nacional de Agronomia, 1953. 323 p. (Série Didática n. 10).

MARICONI, F. A. M. As saúvas. São Paulo-SP: Agronômica Ceres, 1970. $167 \mathrm{p}$.

MARINHO, C. G. S.; OLIVEIRA, M. A.; ARAÚJO, M. S.; RIBEIRO, M. M. R.; DELLA LUCIA, T. M. C. Voo nupcial ou revoada de formigas-cortadeiras. In: DELLA LUCIA, T. M. C. Formigas-cortadeiras: da biologia ao manejo. ViçosaMG: UFV, 2011. p. 165-172.

OLIVEIRA, M. A.; ARAÚJO, M. S.; MARINHO, G. C.; RIBEIRO, M. M. R.; DELLA LUCIA, T. M. C. Manejo de formigas-cortadeiras. In: DELLA LUCIA T. M. C. Formigascortadeiras: da biologia ao manejo. Viçosa-MG: UFV, 2011. p. 400-419.
RODRIGUES, A.; SILVA, A.; BACCI JÚNIOR, M.; FORTI, L. C.; PAGNOCCA, F. C. Filamentous fungi found on foundress queens of leaf-cutting ants (Hymenoptera: Formicidae) Journal Applied Entomololgy, Hoboken, v. 134, v. 342-345, 2010.

SILVA, R. J.; DINIZ, S.; VAZ-DE-MELLO, F. Z. Heterogeneidade do habitat, riqueza e estrutura da assembléia de besouros rola-bostas (Scarabaeidae: Scarabaeinae) em áreas de cerrado na Chapada dos Parecis, MT. Neotropical Entomology, Londrina-PR, v. 39, p. 934-940, 2010.

SILVEIRA, F. A. O.; SANTOS, J. C.; VIANA, L. R.; FALQUETO, S. A.; VAZ-DE-MELLO, F. Z.; FERNANDES, G. W. Predation on Atta laevigata (Smith, 1858) (Formicidae: Attini) by Canthon virens (Mannerheim, 1829) (Coleopptera: Scarabaeidae). Tropical Zoology, Italy, v. 19, p. 1-7, 2006.

VASCONCELOS, H. L. Habitat selection by the queens of the leaf-cutting and Atta sexdens L. in Brazil. Journal of Tropical Ecology, Cambridge, v. 6, p. 249-252, 1990.

VAZ-DE-MELLO, F. Z.; LOUZADA， J. N. $\quad$ C.; SCHOEREDER, J. H. New data and comments on Scarabaeidae (Coleoptera: Scarabaeoidea) associated with Attini (Hymenoptera: Formicidae). The Coleopterists Bulletin, Washington, v. 52, p. 209-216, 1998. 